\title{
Editorial: Introducing this Special Issue on Data Librarianship
}

I am delighted to be introducing this special issue of the International Journal of Librarianship devoted to data librarianship and academic data services. The topic is a timely one. Data has been receiving increased attention as a topic for librarianship over the last few years as ordinary desktop computers become able to crunch larger and larger datasets. In addition to the clear need for better techniques for storage and access, regulatory frameworks have played a role. Many government bodies, funding agencies and academic journals are mandating data preservation and sharing as part of a general push for greater academic transparency. Academic data services, both established and new, are stepping forward to help researchers meet these requirements.

In Canada and the U.S., data services often began with the need to deliver what were then considered large quantities of government data on tape to local researchers, while in Europe and parts of Africa, the founding of national data archives played a significant role. In China data services have taken off with the need to track and manage quantities of faculty-produced datasets, a need that universities around the globe are grappling with. Over time, the issue of how to handle large quantities of data has moved from being a technical one to being one of documentation, description, sharing, and knowledge transfer - a challenge librarians are uniquely positioned to deal with given our experience with cataloguing, organization, and information literacy.

Several books and other publications (including two reviewed in this issue) have been published recently that attempt to help librarians and libraries cope with what is for many a new role. However, to the best of my knowledge most of what is currently available in English focuses on North America and, occasionally, Great Britain. But data is a global concern for researchers, for libraries, and in the end, for society. While the collection of articles and commentaries presented here do not quite span the globe, several comparative perspectives are presented.

What is an academic data service? What types of services do different libraries and organizations offer? What are the common elements that stretch across borders? How can data services and concepts enrich other aspects of academic library service? In this issue, our contributors grapple with these questions and more as they explore diverse aspects of this growing specialty in our profession.

\section{In this Issue}

Meryl Brodsky reports on a syllabus study of data literacy requirements at her institution's business school. She looks at the factors associated with varying data literacy requirements (including some differences she found surprising) and discusses the implications for librarians looking to offer data literacy programs. 
Shu Liu interviewed library users at her institution to analyze researcher needs across the research lifecycle and gauge how the Chinese subject service model works in meeting those needs. Western readers may be particularly interested in some of the unique and unfamiliar aspects of Chinese academic librarianship, such as "Discipline Support Service," in which librarians team up with administration to provide evaluation of programs.

Heidi Winkler and Joy Perrin turn to curation of massive digital collections, focusing on the ways that access to large federated collections can influence decisions and practices at individual institutions. They discuss some of the difficult stewardship decisions that need to be made given limited resources, including deselection.

Some academic libraries have been providing services ranging from digital curation to data literacy for half a century now. Chiu-chuang Chou gives a historical perspective on the development of data services at her institution and provides a "Data Services 101" that outlines the key sources a budding data librarian should consult.

And in our last featured article, $\mathrm{LiLi} \mathrm{Li}$ turns to the role of data in library evaluation. The LibQUAL survey is widely used in North America, and he provides a case study that incorporates a thoughtful discussion of how librarians can use readily available tools to learn more from their survey data.

\section{Commentary}

Two commentary articles provide a wide-ranging look at the field of data librarianship as it is practiced. The first is a collection of virtual interviews conducted with an international panel of well-known and influential data librarians, archivists and educators. Our six interviewees generously shared highlights of their careers, observations on how the field has evolved over time, and words of advice for people and institutions looking to get started in data services.

The second commentary is a dialog between two data librarians, one based in China, the other in Canada, comparing the development of academic data services at their respective institutions and noting some key similarities and differences. I was very fortunate to have the opportunity to collaborate with Shenqin Yin on this column.

This special issue also includes two book reviews looking at recent publications in data librarianship and a report on a recent conference in China.

Lastly, I would like to thank all the people who contributed. Our authors were a delight to work with, and our many reviewers and copy-editors are indispensable and much appreciated. I particularly would like to thank the panel of international experts who generously shared their thoughts. All the members of the Editorial Team need to be thanked as well, and especially Editorin-Chief Guoying Liu, who developed the concept for this special issue and invited me to help make it a reality.

\section{Kristi Thompson}

\section{University of Windsor}

